\title{
La responsabilidad civil por medicamentos defectuosos, una aproximación de Derecho comparado ${ }^{1}$
}

\section{Tort liability for defective drugs, an approximation from comparative law}

\author{
Juan Carlos Villalba Cuéllar \\ Magíster LLM en Derecho Francés, Europeo e Internacional de Negocios \\ Miembro del grupo en Derecho Privado del Centro de Investigaciones \\ de la Facultad de Derecho de la Universidad Militar Nueva Granada, Colombia \\ Correo electrónico: juan.villalba@unimilitar.edu.co \\ http://orcid.org/0000-0002-3592-9819
}

\author{
Andrea Carolina Pérez Forero \\ Magíster en Derecho con énfasis en Derecho Privado \\ Especialista en Derecho Contractual y en Derecho Comercial \\ Miembro del grupo de Derecho Privado del Centro de Investigaciones \\ de la Facultad de Derecho de la Universidad Militar Nueva Granada, Colombia \\ Correo electrónico: andrea.perez@unimilitar.edu.co \\ http://orcid.org/0000-0002-7163-8365
}

\footnotetext{
1 Este artículo es un producto del proyecto de investigación INV DER 2960 "La responsabilidad civil por productos en el contexto médico-sanitario", correspondiente al grupo de "Derecho Privado", línea de investigación sobre "Responsabilidad civil y seguros" que se adelanta en el Centro de Investigaciones de la Facultad de Derecho de la Universidad Militar Nueva Granada.
} 


\section{Resumen}

El presente artículo comprende una aproximación comparativa sobre el alcance y la naturaleza jurídica de la responsabilidad civil por productos médicos defectuosos en el derecho comparado, particularmente en el caso de Estados Unidos, la Unión Europea y algunos países representativos como Francia, España, Alemania y Colombia. El objetivo es identificar las principales características del régimen de responsabilidad civil aplicable a los daños ocasionados por medicamentos defectuosos, así como algunos desarrollos jurisprudenciales en la materia, que permiten entender y destacar dentro de un contexto comparativo las fortalezas, debilidades, similitudes y diferencias subyacentes entre las distintas fuentes normativas que reconocen el principio de reparación del daño como corolario de la responsabilidad civil en materia de medicamentos defectuosos.

\section{Palabras clave}

Responsabilidad civil, medicamentos, producto defectuoso, daños, responsabilidad objetiva.

\section{Abstract}

This paper includes a comparative approach to the scope and legal nature of civil liability due to defective medical products in comparative law, particularly in the case of the United States, the European Union and some representative countries such as France, Spain, Germany and Colombia. The objective is to identify the main characteristics of the civil liability regime applicable to damages caused by defective drugs, as well as case-law developments in the matter, which allow to understand and highlight within a comparative context, the strengths, weaknesses, similarities and differences that underlie the different law sources that recognize the principle of reparation of the damage as a corollary of civil liability regarding defective medicines.

\section{Key Words}

Tort liability, pharmaceutical, defective drugs, damages, strict liability.

\section{Cómo citar este artículo:}

JCV Cuéllar y AC Pérez Forero (2020). La responsabilidad civil por medicamentos defectuosos, una aproximación de Derecho comparado Revista de la Facultad de Derecho y Ciencias Políticas, 50 (133), pp. 480-515. doi: http://dx.doi.org/10.18566/rfdcp.v50n133.a12

Recibido: 19 de febrero de 2020

Aprobado: 04 de junio de 2020 


\section{Introducción}

El acelerado desarrollo tecnológico e industrial que se ha venido experimentando en buena parte del mundo occidental durante estas últimas décadas ha conllevado a un nuevo paradigma del concepto de producción de escala de bienes y servicios, cuyas proporciones y exigencias sobrepasan en muchos casos la capacidad de los mercados locales y las industrias especializadas, en un afán por satisfacer las necesidades de una demanda cada vez mayor de usuarios y consumidores. Las dinámicas de mercado y de consumo masivo de productos también están generando que las grandes compañías fabricantes destinen la mayor parte de sus recursos a la optimización de procesos internos para ampliar la cobertura y el alcance de los bienes y servicios que suministran, bajo estándares de calidad cada vez más exigentes y regulados.

De manera paulatina, en los diferentes ordenamientos jurídicos se han implementado instrumentos normativos de control, regulación y se han robustecido sus regímenes de responsabilidad civil para que —a través de las autoridades, administrativas y judiciales competentes - se puedan moderar, prevenir o resarcir los efectos nocivos a que puede conllevar por sí misma la producción en masa de bienes y servicios. Efectos nocivos que pueden ir desde la mera vulneración de derechos por el incumplimiento de deberes de garantía y seguridad de los productores, hasta la materialización de daños y perjuicios a la salud y el patrimonio de los consumidores en su interacción con productos peligrosos y defectuosos, relacionados con errores de diseño, fabricación o falta de información suministrada por el fabricante. Fue así como surgió una regulación especial de la responsabilidad civil por productos defectuosos que tiene ya décadas de existencia y desarrollo jurisprudencial en el derecho comparado y sobre todo en el contexto anglosajón.

En este escenario, dentro del universo de productos, bienes y servicios ofrecidos al público concurren algunos de características especiales como los medicamentos cuyo consumo lleva implícito un riesgo para la salud de los mismos pacientes. Además, estos dependen en muchos casos de un proveedor idóneo o de un profesional de la medicina asertivo para que, en vez de agravar los síntomas, por el contrario, los pueda tratar, prevenir, diagnosticar o curar a través del fármaco. En dicha interacción se puede llegar a ver comprometida la responsabilidad del fabricante, cuando el producto es defectuoso desde su creación. Cabe distinguir entonces que la responsabilidad civil por la mala 
praxis médica ${ }^{2}$ corresponde a un régimen distinto al relacionado con el producto médico defectuoso, este último es el que se pretende analizar.

Ahora bien, la existencia de un defecto en el producto no es suficiente para determinar la imputación de responsabilidad civil en cabeza del productor, pues se deben acreditar unos presupuestos jurídicos relacionados con la existencia del daño y el nexo de causalidad entre el defecto del producto y el daño causado, el cual prosperaría en un escenario donde no concurran causales eximentes de responsabilidad a favor del productor.

En este orden de ideas, el presente artículo pretende establecer de qué forma se encuentra regulado este régimen de responsabilidad civil por producto médico defectuoso en sus diferentes modalidades alrededor de los sistemas normativos más representativos y experimentados en la materia. Tal es el caso de la Unión Europea, Estados Unidos, Alemania, Francia, España y, de manera particular, su incidencia o recepción normativa en Colombia. La metodología planteada es método dogmático analítico enfocado en la revisión y análisis normativo con un gran componente de derecho comparado.

En tal sentido y para abordar esta temática, el presente artículo se desarrolla de la siguiente forma: en una primera parte se aborda todo lo relacionado con el alcance y la naturaleza jurídica del producto defectuoso en Colombia, donde se analiza el fundamento legal, jurisprudencial y la forma en que se encuadra dicha regulación con los productos médicos. En la segunda parte se analiza el tratamiento jurídico en la materia sobre el producto médico defectuoso y la forma de encuadramiento dentro del régimen de responsabilidad civil en el derecho comparado, específicamente en ordenamientos como el derecho común europeo, los casos de Alemania, Francia y España, asimismo se hace referencia al Derecho de los Estados Unidos, donde tuvo sus primeros desarrollos la materia. Finalmente, se relacionan las conclusiones del estudio comparativo.

2 Ver más en la Sentencia SC7110 del 24 de mayo de 2017 de la Corte Suprema de Justicia, la cual define que: "Se orienta en función de los principios de beneficencia y no maleficencia o primun non nocere del paciente".

Por su parte, Wilson Ruiz (2004) precisa que: “Con respecto a la mala práctica médica, esta se podría definir como una situación de impericia, negligencia o indolencia profesional, donde el galeno produce un resultado que no previó, que no anticipó y que sin embargo era (sic) anticipable, representable y objetivamente previsible. $Y$ donde la imprudencia grave es entendida como la omisión de todas las precauciones exigibles que debieron adoptarse en el suceso o evento de que se trate, o al menos de las más elementales o rudimentarias y es sancionada a título de delito" (p. 200). 


\section{Régimen de responsabilidad civil por producto médico defectuoso en Colombia}

De acuerdo con Velásquez (2016), la expansión del derecho de responsabilidad ha sido de tales dimensiones que, hoy por hoy, se puede decir que se trata de una disciplina casi autónoma del derecho. Una de sus variables temáticas más debatidas es el ámbito de la responsabilidad civil por producto defectuoso dentro del régimen de derecho al consumidor, con ocasión de las controversias que inevitablemente se suscitan entre productores y consumidores; pero sobre todo los daños y perjuicios que estos productos defectuosos tienen la potencialidad de causar en la salud y en el patrimonio de sus destinatarios finales.

Para tal efecto, el ordenamiento jurídico reconoce el deber de reparación del daño como un principio fundante, que no se agota en el ejercicio facultativo de la reclamación jurisdiccional o la protección eficaz del menoscabo patrimonial del afectado. Toda vez que permite reivindicar la satisfacción de valores e imperativos sociales relacionados con la seguridad, la idoneidad y la razonabilidad legítimamente exigibles de quien presta un servicio o fabrica un producto. En tal sentido, este principio se traduce en el hecho de que todo daño causado ilícita o injustamente con perjuicio del patrimonio del destinatario de un bien o servicio puesto en circulación al mercado, debe ser reparado en las proporciones y condiciones exigidas por la ley, conforme al principio de la reparación integral del daño. En palabras de Tamayo:

la institución actual de la responsabilidad civil por productos defectuosos tiene por finalidad la indemnización de los daños por muerte o lesiones a las personas o por el deterioro o destrucción física de bienes de terceros que sea o no adquirentes del producto defectuoso, como consecuencia de un producto inseguro a raíz de un defecto de diseño, de fabricación o de presentación. (2016, p.26)

En estos términos, se pronunció el constituyente cuando al tenor del inciso segundo del artículo 78 de la Constitución Política (1991), estableció una versión más amplia del mencionado principio, al afirmar que: "Serán responsables, de acuerdo con la ley, quienes en la producción y en la comercialización de bienes y servicios, atenten contra la salud, la seguridad y el adecuado aprovisionamiento a consumidores y usuarios”. 
A su turno, la Ley 1480 de 2011 (Estatuto del Consumidor, 2011, ley 1480) le imprimió una garantía mayor, con la posibilidad de imputación solidaria en el marco de la responsabilidad civil, dentro del siguiente tenor:

El productor y el expendedor serán solidariamente responsables de los daños causados por los defectos de sus productos, sin perjuicio de las acciones de repetición a que haya lugar. Para efectos de este artículo, cuando no se indique expresamente quién es el productor, se presumirá como tal quien coloque su nombre, marca o cualquier otro signo o distintivo en el producto. Como daño, se entienden los siguientes:

1. Muerte o lesiones corporales, causadas por el producto defectuoso;

2. Los producidos a una cosa diferente al producto defectuoso, causados por el producto defectuoso.

Lo anterior, sin perjuicio de que el perjudicado pueda reclamar otro tipo de indemnizaciones de acuerdo con la ley.

Este desarrollo legislativo resultó novedoso en el ordenamiento jurídico colombiano, pues los antecedentes normativos que existían sobre responsabilidad por producto defectuoso solo apelaban a una responsabilidad genérica en torno a la idoneidad y calidad de los bienes fabricados, como lo expresaba en su momento el Decreto 3466 de 1982. Este no diferenciaba entre responsabilidad derivada por la calidad del producto y responsabilidad derivada por los daños y perjuicios causados (Villalba, 2012).

La evolución normativa también ha sido evidente en el régimen de responsabilidad civil aplicable por productos defectuosos, pues hemos pasado de la doctrina de los vicios redhibitorios en la cosa y del deber de acreditar la culpa del productor, al campo de la responsabilidad objetiva y extracontractual (Villalba, 2014).

Para Velásquez (2016) es claro que el régimen de responsabilidad civil por producto defectuoso limitado exclusivamente al contrato no responde a las necesidades o retos que suponen este tipo de controversias, tampoco resuelve las problemáticas que genera encuadrar esta forma de responsabilidad con las prestaciones y reclamaciones a que tiene derecho el perjudicado. No obstante, se puede decir que a partir de la entrada en vigencia del Estatuto del Consumidor (2011) se lograron abordar algunas de las cuestiones y problemáticas propias de este régimen, frente a las tendencias internacionales, toda vez que: 
a. Se determinó el régimen de responsabilidad objetiva, bajo el cual no es necesario probar la culpa del productor.

b. Se incluyó que tanto productor como vendedor o expendedor responden de manera solidaria por las obligaciones que se generen en virtud del daño causado al afectado, sin perjuicio del derecho de repetición entre uno y otro.

c. Se implementaron causales eximentes de responsabilidad a favor del productor, tales como la fuerza mayor o caso fortuito, la culpa exclusiva del afectado, el hecho de un tercero, la no puesta en circulación del producto, el cumplimiento de un imperativo legal relacionado con la elaboración, rotulación o empaquetamiento del producto y la que se ha denominado de riesgo de desarrollo ${ }^{3}$.

d. Se imprimió la carga de la prueba en cabeza del afectado, con el deber de probar el defecto del producto, el daño y el nexo de causalidad entre este y aquel. También se dispuso una presunción de responsabilidad cuando el productor viola una norma técnica.

e. En este régimen en particular, se logró alternar la concomitancia de la culpa del consumidor frente al productor.

f. Se extendió el reconocimiento de los daños causados por el producto defectuoso, además de la salud y la vida del destinatario, a otros bienes o cosas patrimoniales.

g. Se incluyó el deber de información exacta, precisa y oportuna del producto, como otro apéndice de la responsabilidad, con el compromiso de cumplimiento del productor de lo anunciado en la publicidad y la prohibición de engaño en la información, tal y como se advierte en el artículo 23 del Estatuto al Consumidor (2011).

De igual modo, el Estatuto del Consumidor (2011) también definió lo que se debe entender por producto defectuoso ${ }^{4}$, para esto trajo la siguiente definición contenida en el numeral 17 del artículo 5: "Producto defectuoso es aquel bien mueble o inmueble que en razón de un error el diseño, fabricación, construcción, embalaje o información, no ofrezca la razonable seguridad a la

3 Ver más en Esther (2016) cuando analiza el alcance de esta causal en el contexto europeo de la siguiente forma, así: "La problemática del riesgo del desarrollo refiere a los daños causados por un producto, el cual, al momento de su lanzamiento al mercado por un productor o fabricante, era considerado inocuo en función de los métodos de verificación de calidad existentes a ese momento. Sin embargo, y como consecuencia del avance tecnológico, se descubre su potencialidad dañosa" (p. 1).

4 Véase más en Duran (2016), su referencia a Parra Lucán cuando afirma que: "El concepto de producto defectuoso no es equiparable al de 'producto peligroso' aun cuando el carácter defectuoso se vincula en el texto comunitario a la falta de seguridad. Así, por ejemplo, determinados productos de limpieza, medicamentos e incluso ciertos aparatos o electrodomésticos pueden considerarse peligrosos, pero, con las advertencias e instrucciones pertinentes y usados correctamente ofrecen la seguridad que cabe legítimamente esperar" (Duran Fernández, 2016, p. 432). 
que toda persona tiene derecho"(2011). Con respecto a esta definición, Villaba (2012) hace una importante precisión entre, por un lado, lo que se supone es la obligación de garantía, debido a la falta de idoneidad, calidad y seguridad del producto; por otro lado, la responsabilidad civil, cuando el producto defectuoso genera daños y perjuicios al consumidor, que son susceptibles de ser indemnizados mediante una demanda ante la jurisdicción civil.

Ahora bien, con respecto al producto médico defectuoso se puede decir que en principio le son aplicables las mismas reglas del Estatuto del Consumidor (2011) y del régimen de responsabilidad civil, como si se tratara de cualquier producto del mercado. Sin embargo, las relaciones de consumo de este producto involucran la intervención necesaria entre varios sujetos: primero, el fabricante o importador del producto; segundo, el proveedor o vendedor del mismo o un profesional de la medicina, en el caso de los médicos tratantes que lo prescriben; por último, el consumidor o paciente destinatario. En cualquier caso, es claro que el Estatuto del Consumidor (2011) no precisa un régimen especial en materia de productos médicos defectuosos.

Lo que se ha podido evidenciar es que en el régimen de responsabilidad civil colombiano por producto defectuoso tuvo un desarrollo previo de carácter jurisprudencial. Esto se puede observar en algunos pronunciamientos de la Corte Suprema de Justicia, particularmente en las sentencias del 30 de abril (Corte Suprema de Justicia, Sala de Casación Civil, Exp. 258993193992 199900629 01) y 24 de septiembre de 2009 (Corte Suprema de Justicia, Sala de Casación Civil, Exp 05360-31-03-001-2005-00060-01). No obstante, estas sentencias se refieren al resarcimiento de perjuicios ocasionados por productos defectuosos, que no corresponden al ámbito farmacéutico. Dicho sea de paso que lo predicado en estas sentencias quedó recogido básicamente en la regulación de la Ley 1480 de 2011 (Ley 1480, 2011). Empero, en el caso colombiano no existe hasta la fecha antecedente jurisprudencial, a partir del cual se haya obligado a un laboratorio o farmacéutica a responder por los daños causados a los consumidores del medicamento.

Cabe agregar que el derecho colombiano cuenta con una normatividad que regula la puesta en el mercado y la circulación de los medicamentos que imponen obligaciones de información, calidad y seguridad a los productores e importadores de los mismos. Al respecto, se destacan el Decreto 374 de 1994, el Decreto 677 de 1995 y el Decreto 2200 de 2005, entre otra normatividad cuyo control está a cargo del INVIMA como autoridad en la materia. 
Por consiguiente, el derecho colombiano tiene un marco normativo general sobre productos defectuosos aplicable a los medicamentos y algunas normas especiales, que imponen obligaciones a productores y proveedores de esto productos.

\section{Antecedentes y tratamiento normativo en el derecho comparado sobre responsabilidad civil por medicamento defectuoso}

En el ámbito del derecho comparado, son diversas las fuentes de regulación y regímenes especiales de responsabilidad civil en materia de bienes y productos defectuosos. La diversidad de normas referidas sobre regulación, control y responsabilidad civil por la elaboración y distribución de tales productos encuentra sus mayores fundamentos en los modelos normativos desarrollados en Estados Unidos y la Unión Europea, esta última a través de sus directivas como es el caso de la No. 85/374/CEE del Consejo de 25 de julio de 1985.

En el contexto de Estados Unidos, un antecedente importante lo constituyeron algunos casos emblemáticos como el de MacPherson v. Buick Motors Co. 217 N.Y. 382, 111 N.E. 1050 de 1916 ante el Tribunal de Apelaciones del Estado de Nueva York, a través del cual se forjó el principio de responsabilidad del fabricante por los daños que causa la puesta en circulación de un producto inseguro y defectuoso (Duran, 2016). Aunque la realidad normativa norteamericana $^{5}$ sobre responsabilidad civil en la materia es parcialmente uniforme en algunos Estados, ya en otros la responsabilidad del productor fue limitada a la existencia de culpa o negligencia propiamente dicha, de acuerdo con Henderson \& Twerski (como se citó en Duran, 2016). Adicionalmente, hay Estados que le dan preferencia a la concurrencia de culpa del afectado (cuando ha sido causada) como elemento mitigador de la indemnización a que tendría derecho. El desarrollo jurisprudencial de la materia en el ámbito norteamericano implicó el paso paulatino de una responsabilidad limitada por la relatividad del contrato, a un ámbito de responsabilidad extracontractual objetivo, a cargo del

5 Véase más en: Evolución de la Responsabilidad del fabricante en Estados Unidos y su influencia en el Derecho Comparado, dentro del cual Marcela Tabakian (2015) sostiene que: "El régimen de responsabilidad por productos en Estados Unidos ha servido como modelo en la Unión Europea y en Latinoamérica [...] la historia de la responsabilidad del fabricante es de creación progresiva. Se entiende por tal el proceso de incorporar a las acciones existentes, nuevos elementos para el reclamo de daños causados por productos defectuosos, que han complementado más que reemplazado previas bases de responsabilidad" (p. 59). 
fabricante derivada de los daños ocasionados por productos defectuosos, tal y como lo describe muy bien Munar (2013).

De otro lado, como se había indicado la entonces Comunidad Europea, hoy Unión Europea, desarrolló una serie de directrices normativas importantes sobre la materia. Un primer antecedente destacable lo encontramos en la Directiva No. 85/374/CEE del Consejo de 25 de julio de 1985: "relativa a la aproximación de las disposiciones legales, reglamentarias y administrativas de los Estados miembros en materia de responsabilidad por los daños causados por productos defectuosos:" 6 . Esta parte de la necesidad de aproximar la divergencia normativa de los Estados Miembros de la Comunidad Europea frente a la circulación de bienes muebles (producidos industrialmente), que se generan y circulan dentro del mercado común europeo. Al mismo tiempo, aborda la problemática de la responsabilidad objetiva del productor ${ }^{7}$, de cara a los crecientes procesos de avances técnicos y tecnológicos que se han venido presentando en sus diversas áreas en buena parte en Occidente durante las últimas décadas.

En efecto, la Directiva No. 85/374/CEE (1985) regula la reparación de los daños causados por muerte y lesiones corporales por el consumo de productos defectuosos, la responsabilidad solidaria y prevalente de los sujetos intervinientes en los procesos de distribución y producción de los productos defectuosos (especialmente importadores y productores); el derecho al resarcimiento del daño, producto de la responsabilidad contractual y extracontractual que puedan generar los productos defectuosos; ${ }^{8}$ las

6 Véase más en el sitio web oficial de la Unión Europea (2019), en torno a la vinculatoriedad de los actos jurídicos y decisiones normativas adoptadas en el denominado corpus legislativo o Derecho Derivado: "Las directivas imponen a los Estados miembros de la UE la consecución de un determinado resultado, dándoles libertad para elegir los medios. Para alcanzar los objetivos fijados por cada directiva, los países de la UE deben adoptar medidas que permitan incorporarla al Derecho nacional (transposición). Las autoridades nacionales están obligadas a comunicar tales medidas a la Comisión Europea. La transposición al Derecho nacional debe producirse en el plazo establecido en la propia directiva (suele ser, por lo general, de dos años). En caso de que un Estado miembro no incorpore una directiva a su Derecho interno, la Comisión puede incoar un procedimiento de infracción".

7 De acuerdo con el artículo $3^{\circ}$ de la Directiva No. 85/374/CEE (1985): "Se entiende por «productor» la persona que fabrica un producto acabado, que produce una materia prima o que fabrica una parte integrante, y toda aquella persona que se presente como productor poniendo su nombre, marca o cualquier otro signo distintivo en el producto".

8 Véase más en el artículo 13 de la Directiva No. 85/374/CEE (1985), en el que libera al demandante de la necesidad de someterse a un régimen de responsabilidad específico (contractual o extracontractual), con tal de no afectar sus derechos a reclamar: "La presente Directiva no afectará a los derechos que el perjudicado pueda tener con arreglo a las normas sobre responsabilidad contractual o extracontractual o con arreglo a algún régimen especial de responsabilidad existentes en el momento de la notificación de la presente Directiva". 
condiciones mínimas de seguridad que debe ofrecer el producto una vez adquirido (diferente a la aptitud del mismo); la concomitancia de culpa por parte del consumidor frente a la posibilidad de reducir o suprimir la responsabilidad que se le pudiera endilgar al productor; la necesidad de probar el daño, el nexo causal y el defecto generador del daño por parte del perjudicado; algunas situaciones excluyentes de responsabilidad por parte del productor, entre otras. A diferencia de la norma colombiana que establece una responsabilidad solidaria de productores y proveedores, la Directiva europea (1985) establece la responsabilidad del productor exclusivamente frente a los consumidores, quien no obstante podrá repetir en contra de los proveedores o distribuidores.

La Directiva No. 85/374/CEE(1985) también considera que sus prescripciones normativas no desconocen que, por efecto del paso del tiempo, los productos se desgastan y pierden sus condiciones de calidad y, ante esta circunstancia, el riesgo no le sería del todo atribuible al productor. Asimismo delimita su campo de acción a los bienes o productos que normalmente se destinan para el uso o consumo privado, artículo 9 (1985) e incluye la posibilidad del daño generado a otros bienes como circunstancia desencadenante de responsabilidad.

Con todo, la Directiva No. 85/374/CEE (1985) trasciende en un régimen de responsabilidad civil objetiva, toda vez que el afectado para acreditar su condición y exigir el resarcimiento del daño causado solo tendría que probar el defecto del producto, el daño causado y el nexo causal entre el defecto y el daño (García, 2017). Es decir que no estaría obligado o limitado a demostrar si hubo culpa, negligencia, impericia, intencionalidad o algún otro elemento de responsabilidad subjetiva imputable al productor.

Ahora bien, en lo que respecta a la naturaleza jurídica del producto defectuoso, el artículo $6^{\circ}$ de la Directiva No. 85/374/CEE (1985) precisa lo siguiente:

1. Un producto es defectuoso cuando no ofrece la seguridad a la que una persona tiene legítimamente derecho, teniendo en cuenta todas las circunstancias, incluso:

a) la presentación del producto; b) el uso que razonablemente pudiera esperarse del producto; c) el momento en que el producto se puso en circulación.

2. Un producto no se considerará defectuoso por la única razón de que, posteriormente, se haya puesto en circulación un producto más perfeccionado. 
Por su parte, Parra Lucán (como se citó en Duran,2016) comenta que:

El concepto de producto defectuoso no es equiparable al de 'producto peligroso' aun cuando el carácter defectuoso se vincula en el texto comunitario a la falta de seguridad. Así, por ejemplo, determinados productos de limpieza, medicamentos e incluso ciertos aparatos o electrodomésticos pueden considerarse peligrosos, pero, con las advertencias e instrucciones pertinentes y usados correctamente ofrecen la seguridad que cabe legítimamente esperar. (p. 432)

En este orden de ideas, es claro que el producto defectuoso no es tal sino en la medida que el mismo posea propiedades o atributos que lo tornen inseguro, también depende de qué tipo de uso le dé el destinatario, pues su utilización indebida conlleva a un riesgo adicional que sobrepasa el propósito o finalidad para la que fue creado. En otras palabras, la seguridad del producto es un atributo necesario del producto al que también está llamado el consumidor a mantener para que sea legítimamente exigible. En caso contrario, la balanza de la responsabilidad civil por el perjuicio causado se va a ver cuestionada a favor del productor.

Adicionalmente, el artículo $7^{\circ}$ de la Directiva (1985) señala cuáles son las circunstancias eximentes de responsabilidad del productor, estas se pueden invocar siempre y cuando se demuestre:

a) que no puso el producto en circulación; b) o que, teniendo en cuenta las circunstancias, sea probable que el defecto que causó el daño no existiera en el momento en que él puso el producto en circulación o que este defecto apareciera más tarde;

c) o que él no fabricó el producto para venderlo o distribuirlo de alguna forma con fines económicos, y que no lo fabricó ni distribuyó en el ámbito de su actividad profesional;

d) 0 que el defecto se debe a que el producto se ajusta a normas imperativas dictadas por los poderes públicos; e) o que, en el momento en que el producto fue puesto en circulación , el estado de los conocimientos científicos y técnicos no permitía descubrir la existencia del defecto; f) o que, en el caso del fabricante de una parte integrante, el defecto sea imputable al diseño del producto a que se ha incorporado 0 a las instrucciones dadas por el fabricante del producto.

Por tanto, se puede afirmar que si bien es objetiva, no se trata de un régimen de responsabilidad absoluta, pues tiene sus límites y, desde luego, que hay circunstancias que, no siendo del todo eximentes, pueden reducir o suprimir la 
responsabilidad civil del productor, como sucede cuando hay concomitancia de culpa $^{9}$ del consumidor, pese a que el producto sea defectuoso.

De regreso al concepto de producto defectuoso, García (2017) afirma que la definición del mismo abarca o incluye los productos médicos y/o farmacéuticos como bienes muebles. Estos pueden padecer, sin duda, o adolecer del atributo de la seguridad y, por consiguiente, ser defectuosos.

En tal sentido, agrega que no se trata de establecer si fueron defraudadas o insatisfechas las esperanzas del consumidor frente al producto médico para suponer que es o no defectuoso; sino que es necesario acreditar si el producto no ofreció la seguridad necesaria a la que el consumidor tiene el legítimo derecho de recibir del productor. De no ser así: "podría suceder que un producto, pese a cumplir todos los niveles reglamentarios de seguridad establecidos, fuese considerado defectuoso porque los consumidores o usuarios esperasen de él una mayor seguridad que la realmente ofrecida” (García, 2017, p. 3).

En estos términos, García (2017) afirma que, tratándose de medicamentos ${ }^{10}$, el elemento que debería ofrecer la seguridad a la que legítimamente tienen

$\overline{\text { En efecto, el numeral }} 2^{\circ}$ del artículo $8^{\circ}$ de la Directiva No. 85/374/CEE (1985) señala que: "La responsabilidad del productor podrá reducirse o anularse, considerando todas las circunstancias, cuando el daño sea causado conjuntamente por un defecto del producto y por culpa del perjudicado o de una persona de la que el perjudicado sea responsable".

10 Véase más en: Evolución de la Responsabilidad del fabricante en Estados Unidos y su influencia en el Derecho Comparado, dentro del cual Marcela Tabakian (2014) refiere el caso Thomas and Wife v. Winchester, 6 N.Y. 397 del año de 1852, el cual resume así: "' el consumidor compra un medicamento que había sido etiquetado erróneamente por el fabricante. Se etiquetó como diente de león un extracto de belladona. El primero de ellos una medicina casi inocua, el segundo administrado en la dosis que corresponde al diente de león puede causar daños severos a la salud de la persona que lo ingiere llevando incluso la muerte. El actor demandó al farmacéutico, al distribuidor y al fabricante. El distribuidor y fabricante alegaron, que el comprador tenía con ellos un vínculo demasiado remoto como para resultar condenados. La Suprema Corte de Nueva York, cita la regla general en la materia que hasta el momento era la siguiente: "... un contratista, fabricante, vendedor o proveedor de un artículo no es responsable frente a terceros que no tienen relaciones contractuales con él por negligencia en la construcción, la fabricación o la venta de dicho artículo" (Cooley en agravios 3ed, 1486). Sin embargo, se aparta de dicho concepto por los siguientes fundamentos: "... la responsabilidad del fabricante y el vendedor se extiende a terceros sólo cuando el artículo fabricado y comercializado es inherentemente peligroso." Y continúa: "Aceptar que para poder reclamar el consumidor final debe acreditar una relación contractual con el fabricante, determinaría que el fabricante nunca fuera responsable respecto del consumidor final. Esta regla no debe aplicarse en los casos en los que los productos venidos son inherentemente peligrosos. Debe considerarse que existe una garantía implícita cuando la naturalmente el producto es peligroso para otros, especialmente en los casos en los que ha sido hecho en forma negligente. Negligencia es un tipo de responsabilidad civil, y se encuentra en el límite entre la responsabilidad civil y contractual." La Corte finalmente condena a toda la cadena y sienta como precedente que, en casos de productos inherentemente peligrosos, existe por un lado una garantía implícita de que el producto debe adecuarse a su función y en segundo lugar, que pese a que el consumidor final no tiene una relación contractual directa con el fabricante éste debe igualmente responder de su negligencia frente al consumidor final"' (Tabakian, 2014, p. 61). 
derecho los destinarios del producto, son las indicaciones que se detallan cuando se pone a disposición del público. En otras palabras, es a través del consumidor, que en este caso sería el paciente, como se podría medir el grado de seguridad legítimamente esperable del producto farmacéutico ${ }^{11}$.

No obstante, resulta claro que no se le puede restar importancia a las decisiones del productor frente a la elaboración y distribución del producto farmacéutico, pues en la mayoría de los casos estas resultan ser aún más determinantes a la hora de establecer la responsabilidad civil por los daños causados, que las decisiones adoptadas por los propios consumidores en el uso de estos productos.

Esto es así debido a que los medicamentos son productos indispensables con un desarrollo más complejo en su elaboración, los cuales no solo deben responder a exigencias de calidad y seguridad para el consumo humano; sino que deben cumplir con requisitos y estándares mínimos para su distribución con el propósito de atender o mejorar necesidades concretas de salud, para generar el menor efecto negativo posible en la salud de los consumidores. Es por este motivo que tienen un nivel de control más intenso que el de cualquier otro producto en el mercado (Ramos, 2005) y, por regla general, existen entidades estatales que controlan previamente las condiciones de calidad y puesta en el mercado de los medicamentos o dispositivos médicos.

Para el contexto norteamericano, por ejemplo, la regulación en la información y producción de medicamentos, vacunas, alimentos y otros productos biológicos (humanos y veterinarios) que desarrollan diversas compañías farmacéuticas está a cargo de la Food and Drug Administration (FDA) conocida por sus siglas en inglés. Entidad estatal cuyo origen se remonta a la aprobación de la Pure Food and Drugs Act (Ley de la Pureza de los Alimentos y Medicamentos) de 1906.

11 Ver más información sobre la percepción de la industria farmacéutica frente al concepto del producto defectuoso dentro del Cuarto Informe sobre la aplicación de la Directiva 85/374/CEE del Consejo de 25 de julio de 1985, UE (2011), que en uno de sus apartes precisa que: "Representantes de la industria farmacéutica en Europa consideran que el régimen de responsabilidad que establece la Directiva no tiene suficientemente en cuenta que el sector de los medicamentos está muy reglamentado. En su opinión, a la hora de analizar el carácter defectuoso del producto y la responsabilidad del productor debería tomarse en consideración el hecho de que la utilización de medicamentos esté sujeta por lo general a la evaluación externa de los profesionales de la salud (entre ellos, por ejemplo, médicos, enfermeros o farmacéuticos) y que el productor no disponga de control sobre la manera en que se prescriben y administran los medicamentos" (p. 9). 
Por su parte, en el plano europeo se encuentra la Agencia Europea de Medicamentos (EMEA) ${ }^{12}$, un ente de control interventor que de forma similar a FDA regula la seguridad, comercialización y autorización en la fabricación de medicamentos, tal y como lo menciona Ramos (2005) en el siguiente extracto:

Después de la comercialización, la Agencia reguladora supervisa la seguridad del medicamento realizando un seguimiento de esta relación riesgo-beneficio, que se concreta en la adopción de medidas que van, desde la simple actualización del prospecto o de la ficha técnica del medicamento, hasta la retirada o recuperación del producto para los casos más graves de puesta en peligro de la salud pública. (p. 4)

Parafraseando a Garber (2013), la FDA tiene dos fases de regulación: una antes de autorizarse la venta del producto farmacéutico (que está en fase de estudios clínicos o de laboratorio) y otra después de que el medicamento ha sido introducido al mercado estadounidense (pos-comercialización). El proceso de aprobación está sometido al cumplimiento de unos requisitos legales exigidos al fabricante y cualquier alteración o modificación posterior que este le pretenda dar a las propiedades químicas del medicamento hará que se considere como un medicamento nuevo, por lo que el fabricante deberá empezar el trámite desde el principio para una próxima aprobación. Esto es así por cuanto el medicamento tiene un diseño auténtico y unas características únicas desde su aprobación por la FDA.

En lo que corresponde a las instalaciones físicas para la fabricación del producto médico, estas también son reguladas antes y después de la aprobación por parte de la FDA del mismo modo, tal y como lo sostiene Garber (2013):

Antes de que un medicamento pueda venderse en los Estados Unidos, la FDA y el patrocinador deben ponerse de acuerdo sobre el etiquetado del producto, que [debe incluir] información de riesgo o seguridad, como advertencias sobre efectos secundarios, contraindicaciones, medicamentos contra medicamentos. Interacciones, e indicaciones aprobadas para su uso. El etiquetado de una droga es, por ley, uniforme en todos los estados. (p. 16)

12 Ver más, en el sitio web de Agencia Europea de Medicamentos (europa.eu) (2019), que señala como funciones principales de la misma: "la autorización y el seguimiento de los medicamentos en la UE. Para poder comercializar sus productos, las empresas deben solicitar la autorización de cada uno de ellos, que es emitida, en su caso, por la Comisión Europea. La autorización les permite comercializar el medicamento en cuestión en toda la UE y el EEE. Dado el amplio alcance del procedimiento centralizado, la mayoría de los medicamentos verdaderamente innovadores que se comercializan en Europa son autorizados por la EMA". 
En este contexto, Garber (2013) comenta que, en la órbita de la responsabilidad civil, a los medicamentos defectuosos le son aplicables las mismas reglas y doctrina de los productos defectuosos en general. Sin embargo, destaca tres (3) categorías principales de defectos que se aplican de manera singular a los medicamentos, tal y como se observa en el siguiente cuadro:

\section{Cuadro 1}

\begin{tabular}{|c|c|c|}
\hline & Denominación & Alcance \\
\hline \multirow[t]{2}{*}{$\begin{array}{c}\text { Defectos } \\
\text { singulares }\end{array}$} & \multirow[t]{2}{*}{ De diseño } & $\begin{array}{l}\text { Los fabricantes son responsables de } \\
\text { los riesgos previsibles por lesiones } \\
\text { advertidas en el producto (según su } \\
\text { diseño) los cuales podrían haberse } \\
\text { evitado utilizando un "diseño alterna- } \\
\text { tivo razonable”*. Es decir, un diseño } \\
\text { que razonablemente fuera menos } \\
\text { peligroso de utilizar para el consu- } \\
\text { midor. En efecto, un medicamento } \\
\text { recetado o un dispositivo médico } \\
\text { no es razonablemente seguro si los } \\
\text { riesgos previsibles de daño son su- } \\
\text { periores con relación a los beneficios } \\
\text { terapéuticos previsibles al paciente; } \\
\text { lo que supone que un profesional de } \\
\text { la salud actúa de forma razonable } \\
\text { evitaría prescribir un producto si es } \\
\text { conocedor de los riesgos previsibles } \\
\text { que este genera frente a los beneficios } \\
\text { terapéuticos que hipotéticamente } \\
\text { se podrían obtener al prescribirle el } \\
\text { medicamento a su paciente. }\end{array}$ \\
\hline & & $\begin{array}{l}\text { * Ver más en Ramos (2005) cuando } \\
\text { sostiene que: "Conforme al criterio de la } \\
\text { alternativa razonable, el medicamento } \\
\text { también sería considerado defectuoso } \\
\text { si la víctima lograra probar que sus } \\
\text { efectos secundarios son superiores a sus } \\
\text { beneficios terapéuticos, bien porque no } \\
\text { es eficaz, bien porque causa daños que } \\
\text { son desproporcionados a los beneficios } \\
\text { que procura" (p. 14). }\end{array}$ \\
\hline
\end{tabular}




\begin{tabular}{|c|c|c|}
\hline & Denominación & Alcance \\
\hline $\begin{array}{c}\text { Defectos } \\
\text { singulares }\end{array}$ & De fabricación & $\begin{array}{l}\text { Los fabricantes son legalmente respon- } \\
\text { sables de los defectos de producción } \\
\text { que se presentan cuando la unidad (es) } \\
\text { de un producto lesione directamente } \\
\text { a un consumidor y no cumpla con las } \\
\text { especificaciones o diseño del fabrican- } \\
\text { te. Tal es el caso de un medicamento } \\
\text { contaminado. } \\
\text { Los fabricantes son responsables de las } \\
\text { lesiones que generen sus medicamen- } \\
\text { tos, sin importar cuán cuidadosos fue- } \\
\text { ran para evitar defectos de fabricación } \\
\text { (o cuán rigurosos sean sus métodos de } \\
\text { control de calidad). } \\
\text { Este defecto se resume en la falta de } \\
\text { instrucción o de advertencia de un } \\
\text { producto médico y es la base de la } \\
\text { responsabilidad civil imputable de un } \\
\text { fabricante. En efecto, la responsabilidad } \\
\text { nace cuando el fabricante omite, estan- } \\
\text { do en el deber de hacerlo, proporcionar } \\
\text { instrucciones o advertencias sobre un } \\
\text { riesgo previsible, especialmente cuando } \\
\text { de tal advertencia se deduzca que con } \\
\text { ella se hubiera podido disminuir o eli- } \\
\text { minar el riesgo. Las advertencias tienen } \\
\text { como destinatario principal al médico } \\
\text { tratante o al profesional de la salud que } \\
\text { prescribe un producto medico en favor } \\
\text { de su paciente. }\end{array}$ \\
\hline
\end{tabular}

Nota: Cuadro de elaboración propia basado en Steven Garber (2013) The Legal and Institutional Settings.

En lo que respecta al defecto de diseño, Ramos (2005) ya había sugerido que - a diferencia del de fabricación y del de advertencia, que de por sí tienen la capacidad de afectar a toda una serie o línea de productos médicos puestos en el mercado - este estaría relacionado con la forma como se ideó y planeó originariamente el producto desde el concepto mismo, la reacción de sus componentes químicos y demás aspectos sustanciales y moleculares esenciales para la existencia, estabilidad y eficacia del mismo. Aunque tal y como lo describe Ramos (2005), toda valoración que se haga sobre un 
producto médico defectuoso en su diseño, conlleva no solo a cuestionar como tal la conducta del fabricante que escogió las condiciones más adecuadas o favorables en su producto; sino al ente o agencia de regulación estatal que, en últimas, es la que va a autorizar la introducción al mercado del producto médico. En cualquier caso, es claro que no podría ser de otra manera, pues en el ámbito judicial no se da el espacio necesario para demostrar un defecto de diseño, como se supone que sí lo hace el propio ente regulador durante el trámite para su aprobación.

Por otro lado, se debe destacar que estas tres categorías permiten evidenciar una singular relación que existe entre varios sujetos que dentro de este contexto intervienen en la cadena o trazabilidad de un producto médico: por un lado, el fabricante o productor; por el otro, el médico o profesional de la salud que prescribe y, por último, el destinatario del medicamento, el paciente o consumidor. Nosotros incluiríamos a los intermediarios y, sobre todo, a los distribuidores o vendedores en farmacia, quienes finalmente van a entregar al consumidor final el producto recetado.

Ahora bien, se podría suponer que el fabricante está blindado frente a posibles demandas de responsabilidad civil con el cumplimiento satisfactorio de las normas de la FDA; pero la realidad es que esto no es siempre cierto y solo en algunos Estados de EEUU se manejan diferentes niveles de protección de los fabricantes de acuerdo con sus propias regulaciones internas ${ }^{13}$, respecto de otros, tal como comentan Garber (2013) y Ramos (2005).

En cualquier caso, se torna evidente que, independiente de algunas variables normativas de protección del fabricante o de defensa de los derechos del paciente o consumidor perjudicado, el régimen de responsabilidad civil aplicado en EEUU y, en general, dentro del ámbito del derecho anglosajón es mixto (objetivo y subjetivo principalmente) y se aplica dentro del contexto de la responsabilidad civil extracontractual, en el que resulta determinante

13 Ver más en The Legal and Institutional Settings de Garber (2013) en el cual afirma que: "“ Con respecto a la jurisprudencia, Schwartz y Goldberg (2005, p. 175), citando a Green (1997) y Noah (2000), escriben que "varios tribunales superiores estatales, como los de California, Washington y Utah, han adoptado, como cuestión práctica, una defensa de cumplimiento normativo para medicamentos recetados". Con respecto a la ley estatutaria, Rosen (2004, fn. 2) informa que siete Estados han promulgado estatutos que protegen los productos farmacéuticos, en diversos grados, desde la responsabilidad del producto basada en cumplimiento de las normas de la FDA". Más específicamente, el estatuto de Michigan proporciona una completa defensa contra la responsabilidad; véase también Miller (2009). Los estatutos en otros estados crean presunciones refutables contra la responsabilidad (New Jersey, Colorado) o proporcionan una defensa solo contra daños punitivos (Arizona, Ohio, Oregon, Utah)"'" (Gerber, 2013, p. 19). 
demostrar la culpa o negligencia del fabricante, especialmente en los casos del defecto de advertencia y de diseño (Tabakian, 2015). No obstante, la carga de la prueba — que recae principalmente en el demandante- gira en torno al deber de demostrar el daño, la causalidad o relación lógica entre el producto médico defectuoso y el daño.

Por otro lado, en el contexto europeo, como se ha podido observar, existe un régimen común más amplio y detallado, liderado por algunas normas como la Directiva No. 85/374/CEE (1985) sobre la aproximación de las disposiciones legales en materia de responsabilidad civil por producto defectuoso, junto con su modificación parcial contenida en la Directiva 1999/34/CE(1999); la Directiva 92/59/CEE(1992) del Consejo relativa a la seguridad general del producto y, un poco más reciente, la adopción del Reglamento del Parlamento Europeo y del Consejo contenido en el documento 864/2007/CEE(2007), sobre las obligaciones extracontractuales en materia civil y mercantil.

De manera que los esfuerzos por aproximar los diferentes ordenamientos y regulaciones de los países miembros de la Unión Europea no ha sido del todo pacífico $^{14}$. En algunos Estados como Alemania, España y Francia se conservan algunas variables, matices y características propias de sus regulaciones internas, respecto de la responsabilidad civil por producto médico defectuoso, como se podrá apreciar a continuación:

\subsection{Alemania}

De acuerdo con Hernández (2018), el régimen de responsabilidad civil alemán hasta antes de la entrada en vigencia de la Directiva No. 85/374/CEE (1985) se encontraba supeditado en el precedente judicial del Bundesgerichtshof, que se enmarcaba dentro de la eterna dialéctica de la summa divisio, es decir, que las

14 A propósito, Hernández (2018) comenta lo siguiente: "'Dos estudios demostraron que la implementación de la Directiva 85/374/CEE (falta año de edición) no ha sido fácil ni pacífica, cuando quiera que, por un lado, existen diferencias entre los modelos nacionales así: "muchas cortes razonan aún en términos de culpa del productor (eventualmente presunta), mientras que otras consideran probado el defecto del producto incluso cuando las causas del daño no son claras", y por el otro, en cuanto al riesgo de desarrollo se encontró que algunos países la aceptaron como causal de exclusión de responsabilidad, que otros la adoptaron parcialmente teniendo en cuenta que excluyeron explícitamente los medicamentos y otros, por su parte, no la adoptaron en sus legislaciones internas como medio de salvar la responsabilidad del productor" (p. 117).

Por otro lado, se debe tener en cuenta que la armonización normativa de los ordenamientos internos de los países miembros con la Directiva No. 85/374/CEE (1985) ha sido controvertida a partir de la interpretación del artículo 13 de la misma (1985). Pues este permite la existencia de otros regímenes de responsabilidad civil especiales o distintos con sistemas de responsabilidad que contractual y subjetiva. 
controversias por responsabilidad de productos defectuosos solo era posible resolverlas a partir de la distinción entre responsabilidad civil contractual y extracontractual. Desde la perspectiva de la responsabilidad contractual, se circunscribía hacia la doctrina de los vicios ocultos de la cosa y las reglas propias del contrato de compraventa. En algunos casos el vendedor o productor se libraba de su responsabilidad, al probar la debida diligencia en la elección o en la vigilancia. Sin embargo, el afectado estaba obligado a probar la culpa del productor si pretendía algún tipo de resarcimiento por el daño causado por el producto. Del mismo modo, en la responsabilidad extracontractual, el vendedor respondía por los daños que causara el producto, cuyos peligros no fueran oportunamente advertidos a sus destinatarios. En ambos sistemas primaba la responsabilidad subjetiva.

Con posterioridad, la balanza se fue inclinando en mayor medida hacia el ámbito de la responsabilidad extracontractual y los jueces aplicaron este régimen desde un enfoque doctrinal, basado en el deber de seguridad hacia el público, que como señala Hernández (2018), se circunscribe en el terreno de la responsabilidad por actos ilícitos, el cual define según Woolcott Oyague y Magnus (como se citó en Hernández, 2018), con el siguiente extracto: “quien dolosa o culposamente lesiona de forma antijurídica la vida, el cuerpo, la salud, la libertad, la propiedad, o cualquier otro derecho de otra persona, está obligado para con ella a la indemnización del daño causado por éste”. Cuando el producto es peligroso y el productor no lo advierte: "se entiende por ese solo hecho que violó esa cláusula general de responsabilidad” (Hernández, 2018, p. 90)

Ahora bien, con posterioridad a la Directiva 85/374/CEE (1985), en Alemania se expidió en el año 1989 una ley en materia de regulación de responsabilidad civil por producto defectuoso (ProdHaftG), entrada en vigencia el primero de enero de 1990. Sin embargo, había una excepción con respecto a su alcance frente a productos médicos, estos quedaron supeditados a la Ley Alemana del Medicamento (AMG), que contemplaba casos de responsabilidad civil por los daños causados por los mismos. A causa de la tragedia de la Talidomida en el contexto germano se expidió el 24 de agosto de 1976, una ley bastante rigurosa con el control de medicamentos y se creó un régimen de responsabilidad objetiva, a tal punto que no considera el riesgo de desarrollo como causal de exoneración de responsabilidad. Esto constituye una excepción frente a lo indicado en la directiva europea sobre productos defectuosos, que sí considera esta causal de exoneración de responsabilidad; pero habilita a los Estados miembros a excluirla o limitarla. Igualmente la normatividad alemana exige 
una póliza de responsabilidad civil a las empresas farmacéuticas para esta clase de eventos. No obstante, esta última ley también fue muy precisa en sus alcances y excluyó de un solo tajo los productos sanitarios, los medicamentos de uso veterinario, los medicamentos para ensayos clínicos que de acuerdo con la ley alemana no estaban sujetos a la aprobación de la AMG, los daños no significativos o que no deriven directamente de un defecto de diseño del producto médico. Infortunadamente, aunque es abundante la seguridad jurídica que ofrece esta normatividad en este país, no atiende de manera coherente la exigencia de la Directiva 85/374/CEE (1985) con respecto a la concurrencia de acciones a favor del afectado que pretenda reclamar por los daños derivados y encajen en cualquiera de los dos regímenes (Ramos, 2003). Al respecto, señala Borghetti (2004) que la AMG a pesar de contener un régimen especial para los daños causados por medicamentos, hasta el año 2002 jugó un papel casi simbólico, dado que no era aplicada por los tribunales. No obstante, la norma fue reformada en el año 2002 a partir de lo cual se creó un régimen más favorable a las víctimas (Borghetti, 2004, p. 135).

En Alemania, a partir de la jurisprudencia de casos emblemáticos como el de la "vacuna de las gallinas" o la tristemente célebre tragedia de la Talidomida, se desarrollaron estándares jurídicos en el ámbito de la responsabilidad civil por producto médico defectuoso, que incluyeron la consolidación del régimen de responsabilidad civil extracontractual del productor, la dinamización en la carga de la prueba en cabeza del productor, una vez la víctima logre acreditar la existencia de un daño a partir de un determinado producto defectuoso y el riesgo de empresa como fundamento de responsabilidad, al considerar que el productor una vez asume la producción de bienes defectuosos, está obligado a resarcir los daños que sean causados por dichos bienes (Hernández, 2018).

En efecto, en el contexto alemán surgiría el caso paradigmático de responsabilidad por medicamentos defectuosos hasta la fecha: la Talidomida. Se trató de un medicamento desarrollado por el laboratorio alemán Grünenthal Gmbh, comercializado entre 1957 y 1963 bajo el nombre comercial de "Contergan", para aliviar los síntomas desarrollados por el embarazo durante los primeros meses. A partir de 1961, serios estudios científicos comenzaron a demostrar que la ingesta del medicamento generaba graves malformaciones en los fetos, principalmente consistentes en el nacimiento de niños sin extremidades, patología que recibió el nombre de focomelia o anomalía congénita, caracterizada en su mayoría por la cortedad de las extremidades, además de otras malformaciones. Entre 1956 y 1962 nacieron en países europeos y en otros países más de doce mil niños con 
malformaciones derivadas de la Talidomida. En Alemania hubo alrededor de seis mil víctimas de este fármaco y las acciones legales emprendidas por estas derivaron en la exoneración de la responsabilidad penal de los directivos de la empresa (Armada, 2015, p. 18) y un acuerdo transaccional entre la empresa y las víctimas, según el cual esta última acordó pagar cien millones de marcos a los primeros, motivo por el cual la Corte de Alemania en su sesión del 18 de diciembre de 1970 declaró la terminación del juicio (Pico, 2017, p. 104). El Ministerio Federal de Salud alemán creó en 1971 una fundación para ayuda a las víctimas de la Talidomida, lo cual implicó la destinación de fondos estatales para apoyar a los discapacitados afectados por el medicamento.

Se advierte entonces que el derecho alemán, a diferencia de la mayoría de ordenamientos jurídicos, cuenta con una norma especial de responsabilidad por medicamentos defectuosos, que subsiste paralelamente con la normatividad general por productos defectuosos.

\subsection{España}

Como señala Parra (2014), España reguló por primera vez el tema a través de la Ley General para la defensa de consumidores y usuarios (LGDCU) del 19 de julio de 1984, fecha en la cual España no pertenecía a la actual Unión Europea (Parra, 2011, p 66). Posteriormente a su ingreso al mercado común se debió integrar a la Directiva 85/374/CEE (1985), la cual aplica como Estado miembro de la Unión Europea y armoniza con sus disposiciones internas sobre la materia, a través de la Ley 22 de 1994, el Decreto Real Legislativo 01 de 2007 y posteriormente el Texto Refundido de la Ley General para la Defensa del Consumidor y Usuarios, conocido como TRLGDCU y otras leyes de acuerdo con García (2017).

Esta última señala que el perjudicado tiene derecho a ser indemnizado por los daños que sean causados por los bienes y/o servicios defectuosos suministrados por el productor y define el producto defectuoso en el artículo 137 (2007) de la siguiente forma:

1. Se entenderá por producto defectuoso aquél que no ofrezca la seguridad que cabría legítimamente esperar, teniendo en cuenta todas las circunstancias $\mathrm{y}$, especialmente, su presentación, el uso razonablemente previsible del mismo y el momento de su puesta en circulación.

2. En todo caso, un producto es defectuoso si no ofrece la seguridad normalmente ofrecida por los demás ejemplares de la misma serie. 
3. Un producto no podrá ser considerado defectuoso por el solo hecho de que tal producto se ponga posteriormente en circulación de forma más perfeccionada.

Dentro de este marco normativo se establece que son ineficaces las cláusulas de exoneración o limitativas de responsabilidad que pretenda el productor; además determina que la carga de la prueba recae en cabeza del afectado, al considerar que deberá probar la existencia del defecto, el daño y el nexo causal entre el primero y el segundo. También refiere que la acción de reparación de daños y perjuicios por producto defectuoso prescribe a los tres años desde la ocurrencia del hecho y respecto de los productos médicos precisa que, el productor no podrá invocar como causal de exoneración el estado de conocimientos científicos y técnicos existentes al momento de la existencia del defecto en el producto. Esta condición se hace extensiva de manera similar a alimentos y productos alimentarios. Cabe anotar que la norma española en lo relativo a la responsabilidad de la administración pública contiene un precepto que la exonera por riesgos de desarrollo, específicamente nos referimos al artículo 34.1 de la Ley de Régimen Jurídico del Sector Público(2015): “no serán indemnizables los daños que se deriven de hechos o circunstancias que no se hubiesen podido prever o evitar según el estado de los conocimientos de la ciencia o de la técnica existente en el momento de producción de aquéllos”, conocida como cláusula de progreso. Esta particularidad pone de manifiesto un doble régimen con un tratamiento diferenciado para la administración pública y los laboratorios farmacéuticos, en cabeza de estos últimos radica la responsabilidad civil por riesgos de desarrollo. Lo que surgió como consecuencia de algunos casos de contaminación por VIH y Hepatitis C en hospitales públicos en los años ochenta y ha sido criticado enfáticamente por la doctrina, ya que se señala al Estado de proteger su propia ignorancia y evadir la responsabilidad objetiva (Pardo, 2013). Esta normatividad que tiene su antecedente en la Ley 4 de $1999,{ }^{15}$ según Valverde y Cabezas, es además contraria a la normatividad europea sobre la materia y la misma Ley 22 de 1994 que transpuso la Directiva europea sobre responsabilidad por productos defectuosos (Valverde y Cabezas, 2009). Al respecto también se ha criticado que incluso bajo el régimen anterior, la víctima tenía que probar la culpa de la administración, lo cual es criticable por constituir una prueba diabólica, es decir, imposible de demostrar. Esto ha llevado autores como Sarrato a sugerir un nivel intermedio de responsabilidad de la administración:

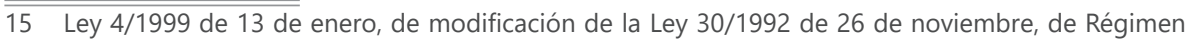
Jurídico de las Administraciones Públicas y del Procedimiento Administrativo Común. 
La Administración autoriza la comercialización de un medicamento y despliega su potestad de control y supervisión a través de mecanismos de farmacovigilancia con el fin de reducir o eliminar en la medida de lo posible el riesgo de producción de daños a la colectividad, pero, como es lógico pensar, no se puede responsabilizar de todas las facetas de la actividad del sujeto autorizado. Por ello, es importante determinar el cumplimiento de los deberes asumidos por la Administración respecto del medicamento en cuestión, valorar el grado de diligencia por ella desplegado, en el sentido de poder discernir si aquella ha podido otorgar una autorización negligente, o si ha adoptado todas las medidas de control de seguridad del fármaco una vez que en su momento procedió a otorgar la autorización del mismo. (2013, p. 232)

La Ley del Medicamento en España, Real Decreto Legislativo 1/2015 de 24 de julio, por el que se aprueba el texto refundido de la Ley de garantías y uso racional de los medicamentos y productos sanitarios, define el medicamento de uso humano como:

toda sustancia o combinación de sustancias que se presente como poseedora de propiedades para el tratamiento o prevención de enfermedades en seres humanos o que pueda usarse en seres humanos o administrarse a seres humanos con el fin de restaurar, corregir o modificar las funciones fisiológicas ejerciendo una acción farmacológica, inmunológica o metabólica, o de establecer un diagnóstico médico. (Ley 1/2015)

Según esta norma solo se tiene como medicamentos: a) Los medicamentos de uso humano y de uso veterinario elaborados industrialmente o en cuya fabricación intervenga un proceso industrial. b) Las fórmulas magistrales. c) Los preparados oficinales. d) Los medicamentos especiales previstos en esta Ley (artículo 8, 2015). Se debe destacar que esta norma establece unas garantías especiales de calidad, seguridad, eficacia, identificación e información en los medicamentos, las cuales refuerzan las obligaciones de productores establecidas en el régimen ordinario de protección al consumidor. Resulta importante la garantía de seguridad, según la cual "los medicamentos, principios activos y materias primas que compongan aquéllos serán objeto de los estudios toxicológicos y clínicos que permitan garantizar su seguridad en condiciones normales de uso y que estarán en relación con la duración prevista del tratamiento" (artículo 12, 2015).

Sin duda, el régimen de responsabilidad civil que se aplica en España por medicamentos defectuosos es objetivo, toda vez que no hay elementos 
subjetivos a considerar en cabeza del productor al momento de impetrar las acciones legales correspondientes.

En cuanto al desarrollo jurisprudencial de la materia en el ámbito español se reseñarán dos casos relativamente recientes de fallos sobre responsabilidad por medicamentos defectuosos. En primer lugar nos referiremos al caso de la Talidomida, este constituye además el caso más importante de responsabilidad por medicamentos defectuosos por las ondas repercusiones que tuvo en los Estados Unidos y en Europa. Para el caso español se traerá a colación porque, a pesar de ser un caso de antigua ocurrencia, en años recientes se profirieron unas sentencias relativas a la responsabilidad derivada por los perjuicios ocasionados por este medicamento. En efecto, la asociación de víctimas de la Talidomida en España conocida como AVITE, inició acciones legales en contra de la farmacéutica Grünenthal Pharma, encaminada a la indemnización de los perjuicios causados a las víctimas. Es así como el Juzgado de Primera instancia de Madrid profirió el día 19 de noviembre de 2013 un fallo en el cual se concedió la indemnización, consistente en multiplicar por 20.000 euros cada punto porcentual de minusvalía reconocida por la autoridad española (Navarro-Michel, 2016). Esta sentencia en segunda instancia fue revocada por la audiencia provincial de Madrid, mediante fallo de octubre 13 de 2014, en el cual se declaró que la acción de responsabilidad civil había prescrito. La asociación demandante interpuso recurso de casación ante el Tribunal Supremo, que desestimó el recurso y confirmó el fallo de la Audiencia Provincial. Este fallo ha causado controversia en la doctrina española, la cual ha analizado el aspecto relacionado con la prescripción de las acciones de indemnización de daños derivados por productos defectuosos, término que según la Directiva europea sobre la materia es de tres años. Sobre este punto señala Navarro - Michel que es importante la distinción entre daños continuados y daños permanentes: "los daños continuados son los que se van produciendo continuadamente, de forma sucesiva o ininterrumpida, aquellos en los que la causa del daño persiste en el tiempo. Los daños permanentes son aquellos que se producen en un momento determinado y se prolongan en el tiempo.” (Navarro- Michel, 2016, p.141). Esta autora dice que la determinación de la fecha de prescripción de la acción es relativa: si se trata de daños continuados, la fecha a partir de la cual se cuenta la prescripción es aquella en que se produce el resultado definitivo; mientras que en el caso de los daños permanentes, la fecha que se tiene en cuenta es aquella en la que se tiene conocimiento del alcance de las secuelas hacia el futuro. Para el caso analizado, el juzgado de primera instancia consideró que los daños eran continuados, posición de la asociación demandante; mientras que la Audiencia Provincial consideró que eran 
permanentes, motivo por el cual tuvo como parámetro principal para contar el plazo de prescripción la fecha máxima de nacimiento de las víctimas de la Talidomida, es decir 1965, sumando los años en que las víctimas cumplirían la mayoría de edad para demandar, es decir 1983, contando además la fecha en que se declaró la situación de discapacidad, por lo cual consideró que la acción estaba prescrita. El Tribunal Supremo confirmó este argumento; mientras que posteriormente en el año 2016 el Tribunal constitucional inadmitió el recurso de amparo interpuesto en contra de ese fallo. El Tribunal Europeo de Derechos Humanos tampoco admitió una demanda interpuesta en 2016 por este asunto, al considerar que "no se observaba ninguna apariencia de violación de los derechos y libertades garantizados por el Convenio de Protección de los Derechos Humanos y Libertades Fundamentales de 4 de noviembre de 1950 o sus protocolos." (Vaquero, 2017, p.278).

En segundo lugar, nos referiremos al caso del medicamento veraliprida, comercializado bajo la marca Agreal en España desde 1983 por el laboratorio Sanofi-Aventis, destinado a combatir los síntomas de la menopausia en mujeres. El consumo del mismo conllevó unas afectaciones en la salud, tales como: problemas neurológicos e incluso alteraciones en el sistema nervioso, que se manifestaban en depresión, cansancio crónico, insomnio, ansiedad, movimientos involuntarios, entre otros. En este caso la autoridad de control española recibió cientos de notificaciones de reacciones adversas del medicamento; sin embargo, el medicamento solo fue retirado 22 años más tarde, cuando el Ministerio de Salud el 20 de mayo de 2005 ordenó la suspensión de comercialización del mismo al encontrar que la relación riesgo-beneficio del medicamento generaba un riesgo de reacciones psiquiátricas y de síndrome de retirada que se consideraron inaceptables. La causa del daño derivó del hecho que a las mujeres españolas se les prescribió el medicamento por largos periodos; sin embargo, en el folleto anexo del fármaco en países como Italia o Francia contenía información adicional sobre los posibles efectos secundarios en caso de ser administrado por más de dos meses. Es decir que se trató de un vicio o defecto de información, en razón de que los laboratorios productores del mismo no publicaron en la ficha de información las advertencias sobre las consecuencias del consumo prolongado del medicamento. En España la farmacéutica que lo distribuyó no incluyó esta información y el medicamento fue recetado largos periodos a pacientes para el tratamiento de la menopausia, con serios efectos secundarios permanentes, que a muchas de ellas les implicaron incapacidades laborales. 
Las víctimas del medicamento a través de asociaciones e individualmente demandaron la indemnización por los vicios en la información del medicamento. No obstante, estas acciones han tenido resultados diversos. El Juzgado de primera instancia No. 12 de Barcelona en fallo de 2006 reconoció el carácter defectuoso del producto y ordenó indemnizar a tres de las dieciocho mujeres demandantes. En igual sentido la sentencia STS 10-7-2014 del Tribunal Supremo español resolvió una demanda interpuesta por 147 mujeres víctimas del Agreal, al confirmar la sentencia dictada por la audiencia provincial de Barcelona (Sección 17ª 7.6.2012), en el sentido de condenar a la demandada, en la medida que modificó la sentencia de primera instancia que absolvía a la empresa demandada para ordenar indemnizar a las víctimas. Al respecto reseñaron Coderch y Ramos:

La AP Barcelona (Sección 17ª 7.6.2012) estima en parte el recurso de apelación de todas las demandantes, revoca la SJPI desestimatoria de la demanda, declara el carácter defectuoso del producto por deficiente información y la consiguiente vulneración de los derechos fundamentales a la libertad, en su vertiente de libertad de elección, y a la integridad física y moral de las actoras, que valora en 3.000 euros en concepto de daño moral. Además, en trece de los casos condena a Sanofi Aventis, S.A. a pagar indemnizaciones que van desde 25,46 a 92.929 euros por los daños físicos sufridos. En los restantes casos, la AP no considera acreditada la relación de causalidad entre el consumo del medicamento y los daños. (Coderch y Ramos, 2014, p.29)

Añade Parra Lucán sobre esta sentencia que la STS 10-7-2014 confirma la condena al laboratorio fabricante con el argumento de "que el medicamento cuestionado es defectuoso por deficiente información contenida en el prospecto y como consecuencia de ello se vulneraron los derechos fundamentales a la libertad, en su vertiente de libertad de elección, y a la integridad física y moral de las actoras” (Parra, 2014, p.7). Las demandas se formulan contra el laboratorio que comercializaba el fármaco en aplicación de la normativa civil plasmada en la Ley 22/94 de 6 julio (1994) de responsabilidad civil por los daños causados por productos defectuosos, la Ley 25/1990 de 20 de diciembre (1990) conocida como Ley del medicamento y el artículo 1902 del Código Civil (1889) (Parra, 2014). Igualmente la doctrina española reseña una sentencia en que el tribunal supremo manifestó que: “Junto al etiquetado, la ficha técnica y el prospecto constituyen vertientes fundamentales del derecho a la información en ámbito del derecho sanitario”, y lo cierto es que en el prospecto de Agreal no se hallaban descritos suficientemente los efectos adversos del 
medicamento, siendo la información en el contenido, según la sentencia recurrida, insuficiente e inadecuada en orden a posibilitar el consentimiento informado completo y suficiente para la ingesta del fármaco"” (Navarro, 2014, p. 174). Al respecto, Lomas destaca la importancia que legalmente puede tener en el ámbito español la ficha técnica del medicamento, pues "tanto desde el punto de vista asistencial como desde una vertiente jurídica, pues en cierto modo condiciona la válida actuación del profesional prescriptor, y determina la responsabilidad en la que puede incurrir el laboratorio” (Lomas, 2014, p. 72). Basta agregar que según la norma española es definida como:

La ficha técnica o resumen de las características del producto reflejará las condiciones de uso autorizadas para el medicamento y sintetizará la información científica esencial para los profesionales sanitarios. La Agencia Española de Medicamentos y Productos Sanitarios aprobará la ficha técnica en la que constarán datos suficientes sobre la identificación del medicamento y su titular, así como las indicaciones terapéuticas para las que el medicamento ha sido autorizado, de acuerdo con los estudios que avalan su autorización. A la ficha técnica se acompañará, preceptivamente, información actualizada del precio del medicamento y, cuando sea posible, la estimación del coste del tratamiento. (Artículo 15.2 del Real Decreto Legislativo 1/2015 de 24 de julio, 2015).

Es decir que se trata de un documento técnico, de conocimiento especializado, que contiene información que se entiende y hace parte de la información esencial del producto, por ende, puede comprometer la responsabilidad civil de los comercializadores del medicamento, así esta no haya sido informada a los consumidores. Lomas recalca el deber legal de los médicos de ceñirse a la ficha técnica, aun cuando en algunos eventos pueden desmarcarse de la misma para prescribir el medicamento por fuera de la ficha técnica, bajo dos requisitos: la inexistencia de alternativa terapéutica y la obtención del consentimiento expreso del paciente (Lomas, 2014).

De otro lado, el Juzgado de Primera Instancia número 3 de Valencia en el año 2013 declaró imprósperas las pretensiones de siete mujeres por declarar prescrita la acción de responsabilidad civil y no probado el nexo causal entre la toma del medicamento y los daños ocasionados.

En tal sentido, se puede afirmar que las sentencias en materia de responsabilidad por medicamentos defectuosos en España han tenido resultados relativos para las víctimas, pues en casos como la Talidomida la 
prescripción jugó a favor de la empresa farmacéutica y en el caso Agreal el nexo causal no ha sido acreditado debidamente por las demandantes.

Se puede concluir, además, frente al derecho español que la normatividad general corresponde a la norma de protección al consumidor, conocida como el TRLGDCU (2007), donde se recoge la normativa europea.

\subsection{Francia}

Similar a la experiencia alemana, Francia superó una fase de la responsabilidad civil contractual y la dependencia determinante de elementos subjetivos de culpa y negligencia en cabeza del productor para responsabilizar el daño civil por productos defectuosos. De igual forma, en el contexto legislativo desarrolló instrumentos normativos complementarios que han sido insertados directamente en el Código Civil francés (1804), con la respectiva armonización a la Directiva 85/374/CEE (1985). Por su parte, el artículo 13864 de la Ley 98-389 precisa que: "un producto es defectuoso en el sentido del presente título cuando no ofrece la seguridad que uno legítimamente puede esperar”(1998).

Ahora bien, en todos los demás aspectos relativos a la responsabilidad civil por producto médico defectuoso, el régimen legal francés no cuenta con una ley especial sobre la materia, a diferencia del caso alemán. Si bien en 2002 el Código de la Salud Pública se introdujo con una regulación amplia sobre el control previo de medicamentos y el régimen de fármaco-vigilancia, la norma regula la responsabilidad de los médicos, que por regla general es un régimen de responsabilidad por culpa; pero excluye el caso en que el producto sea defectuoso según el artículo 1142-1(2000), por esto se aplica la norma que transpone la Directiva de 2005 (Bloch, 2014). Además el retardo del gobierno francés en la trasposición de la Directiva 85/374/CEE(1985), que solamente fue insertada al orden interno en el año 1998, exigió a los jueces franceses la aplicación jurisprudencial de sus principios fundamentales en casos relativos a productos médicos como el caso de la sangre contaminada con VIH en 1995 (Hocquet-Berg, 2018). Se entiende como productor — según la ley francesa y en consonancia con la Directiva europea - toda persona que a título profesional se presente como tal poniendo en el producto su nombre, marca o cualquier otro signo distintivo con ocasión de la venta del producto o cualquier forma de distribución del mismo (artículo 1386-6 del Código Civil, 1804). La reparación del daño según la ley francesa es integral y comprende los perjuicios causados a la persona patrimonial y extrapatrimonialmente, quedando exceptuados los daños causados a otros bienes o al producto mismo (Hocquet-Berg, 2018). 
En cuanto a las causales de exoneración de responsabilidad, en relación con la causal de exclusión de responsabilidad del productor por desarrollo científico o riesgo de desarrollo, la ley francesa no precisa nada respecto de los medicamentos; mientras que sí lo hace respecto de los elementos derivados del cuerpo humano o que provengan de este. En otras palabras, esta legislación parece favorecer al productor de medicamentos con esta causal, pues le permitiría invocar el riesgo de desarrollo para suprimir su responsabilidad por los daños causados a los consumidores, siempre que no se trate de elementos del cuerpo. Esta exclusión particular efectuada en el derecho francés obedeció a un antecedente que tuvo el tema por el caso de sangre contaminada, dado que los jueces franceses crearon un régimen especial de responsabilidad objetiva para este tipo de casos, quedando cubiertos no solamente la sangre sino los productos lábiles y los órganos o tejidos destinados a ser utilizados en un injerto o en la procreación médica asistida (Mascret, 1999). Igualmente, el código civil francés prevé que el productor puede ser responsable, aunque el producto haya sido fabricado bajo el respeto de las normas existentes o haya sido objeto de una autorización de tipo administrativo (artículo 1386-10, 1804), esto implica que la autorización gubernamental de circulación y puesta en el mercado del producto, no produce causal de exoneración del fabricante.

Diversos casos se han presentado en el contexto francés de responsabilidad por medicamentos defectuosos, uno de los más conocidos fue el del medicamento distilbene, más conocido como el DES, por cuanto en los Estados Unidos y otros países también hubo víctimas de este, el cual fue formulado a pacientes mujeres entre 1948 y 1977 para controlar los riesgos de aborto durante el embarazo. Las hijas mujeres de las pacientes que tomaron el medicamento en estado de gravidez presentaron malformaciones uterinas y en la edad adulta problemas de esterilidad, embarazos riesgosos, partos prematuros y algunas veces tumores cancerígenos. Un fallo de la Corte de Versalles de 2011 concedió a un hijo de una paciente que tomó el medicamento una indemnización de 1,7 millones de euros. La Isomerida igualmente fue un medicamento utilizado para controlar el hambre, que se suministró a millones de franceses entre 1985 y 1997; así como el Mediator, medicamento antidiabético retirado del mercado en mayo de 2010, prescrito a 5 millones de franceses entre 1976 y 2009, del cual se estiman entre 500 y 2000 el número de víctimas fallecidas a causa de las complicaciones pulmonares y cardíacas producidas por el medicamento (Hocquet-Berg, 2018). Mediante un fallo del 20 de septiembre de 2017 la Corte de casación francesa ordenó indemnizar a una mujer a la que le fue prescrito el medicamento entre 2006 y 2009 y como consecuencia sufrió una deficiencia aórtica, bajo el entendido para los 
jueces que, una vez probado el posible nexo causal y dado que fue establecido por la corte de primera instancia que el medicamento tenía unos compuestos que por su similitud con otros medicamentos se habían decretado peligrosos, habrían exigido a la sociedad demandada a efectuar investigaciones o por lo menos informar a médicos y pacientes sobre el riesgo del medicamento. Además, la Corte descartó el riesgo de desarrollo como causal de exoneración de responsabilidad (Civ. 1ère, 20 septiembre 2017, $n^{\circ}$ 19-19.643) (Dubois, 2018). El laboratorio fabricante había pagado indemnizaciones a las víctimas sin esperar fallos judiciales por un monto de 115 millones de euros a 3.600 pacientes afectados, hasta el año 2019. Un caso reciente que ha sido muy mediático, pero que tiene varias demandas en curso es el de la Levotiroxina, un medicamento utilizado para tratar los trastornos de tiroides, el cual había sido formulado a millones de pacientes. En 2017 el laboratorio Merck cambió su fórmula por solicitud de la Agencia nacional de seguridad de medicamentos ANSM consistente en remplazar uno de sus componentes, la lactosa por manitol. Con la nueva fórmula miles de pacientes comenzaron a presentar efectos secundarios, tales como fatiga intensa, dolores de cabeza, calambres, depresión. Actualmente cursa una acción colectiva contra el laboratorio en que cada víctima pide como indemnización la suma de 10.000 euros.

Por consiguiente, en el derecho francés el tema de la responsabilidad por medicamentos defectuosos se rige por el régimen europeo de responsabilidad por productos defectuosos; pero se complementa con las normas sobre medicamentos que imponen obligaciones especiales de información y control de la seguridad de medicamentos.

\section{Conclusiones}

A partir de la entrada en vigencia del Estatuto del Consumidor (Ley 1480, 2011) se puede afirmar que Colombia detenta un avance importante dentro de los ordenamientos jurídicos del mundo frente a su preocupación por regular las relaciones y controversias que se suscitan entre consumidores y productores, especialmente por asuntos relacionados con la responsabilidad civil por productos defectuosos, la norma colombiana tiene una gran influencia de la norma europea sobre la materia; aunque su espectro se puede evidenciar más amplio específicamente en la responsabilidad solidaria de productores y proveedores, dado que para el Estatuto (2011) son responsables por los perjuicios ocasionados por el producto defectuoso igualmente los proveedores. Para el caso de los medicamentos, esto podría comprometer la responsabilidad 
de los distribuidores y comercializadores de estos productos frente a las víctimas.

También se puede afirmar que el producto médico defectuoso $\mathrm{y}$, específicamente, el medicamento, tienen los mismos alcances y obligaciones a las que se generan por los daños causados por otros productos defectuosos en general; aunque estos se pueden ver acentuados por las exigencias técnicas de información, calidad y seguridad que les exigen a los fabricantes de estos productos.

Dentro de los ordenamientos jurídicos examinados se evidencia que a excepción de Alemania, el tema de la responsabilidad por medicamentos defectuosos está cobijado por las normas generales de responsabilidad por productos. No obstante, en todos los ordenamientos jurídicos existen normas sobre control de medicamentos que complementan de alguna forma este régimen en temas como información, obligaciones de seguridad y calidad a cargo de los productores.

Algunas características propias de este régimen descansan en la posibilidad de establecer la obligación de indemnizar el daño al productor y/o proveedor para el caso colombiano, en un marco de responsabilidad objetiva, sin que sea necesario probar la culpa del mismo. También se evidencia que el carácter contractual y extracontractual sobre el cual se puede reivindicar el derecho al resarcimiento del daño, pasa a un segundo plano en materia de responsabilidad por defectos de productos.

Con todo, es claro que el régimen de responsabilidad civil colombiano por esta clase de productos ha tenido un desarrollo precario desde la perspectiva del antecedentes jurisprudenciales, ya que se puede observar que existen escasos pronunciamientos de la Corte Suprema de Justicia, particularmente en las sentencias del 30 de abril (Corte Suprema de Justicia, Sala de Casación Civil, Exp. 2589931939921999 00629) y 24 de septiembre de 2009 abril (Corte Suprema de Justicia, Sala de Casación Civil, Exp 05360-31-03-0012005-00060-01); de manera similar, en otras sentencias como la SC7220-2015 de marzo de 2015 de la misma Corte Suprema de Justicia (Corte Suprema de Justicia, Sala de Casación Civil, Rad. 11001-31-03-034-2003-00515-01), las cuales no versaron sobre medicamentos defectuosos y en las que cabe destacar que las pretensiones no prosperaron por falta de prueba del nexo de causalidad. 
Por el contrario, se evidencia que en los otros ordenamientos jurídicos objeto de revisión existe una casuística más bien amplia de accidentes de consumo con medicamentos y un espectro jurisprudencial más extenso, que han permitido avances por esa vía en asuntos de daños masivos a consumidores. Lo que de paso pone de manifiesto ciertos problemas relacionados con el nexo causal, la prescripción de las acciones y las clases de defectos que puede tener un medicamento a la hora de dirimirse un conflicto ante los jueces.

Los casos resueltos por los jueces en el derecho comparado revisado permitieron identificar que los problemas de información en medicamentos son relativamente frecuentes, así como aquellos relacionados con el diseño inadecuado de los mismos. Igualmente se evidencia que aunque se trate de un régimen de responsabilidad objetiva, las cargas probatorias a cargo de los consumidores víctimas son altas y a veces frustran la prosperidad de sus pretensiones. Esto invita a una reflexión acerca de la flexibilización de dichas cargas y, especialmente, lo relativo al nexo causal. Del mismo modo, aparece como importante en esta materia el tema de la prescripción y los términos legales impuestos por los ordenamientos internos para ejercer la acción de responsabilidad civil por medicamentos defectuosos. Sobre este aspecto consideramos que al tratarse en muchos casos de perjuicios de larga cola, es decir, aquellos que se manifiestan luego de largos periodos de ingesta o administración de los medicamentos, los términos de prescripción deben ampliarse por el legislador para ciertos casos o, por lo menos, clarificarse en las normativas nacionales cuáles son los criterios que se tienen en cuenta para contar el momento en que se comienza a contar dicho término de prescripción: aquel en que aparecen los síntomas y se manifiesta primigeniamente el daño o el momento en que la víctima puede conocer realmente el origen del daño y su interés de demandar a un sujeto determinado se concreta como real. Sin duda, estos son temas que ameritan un estudio posterior más decantado.

Asimismo, se puede concluir que en Colombia tampoco se discrimina el riesgo de desarrollo como una causal eximente de responsabilidad para productos médicos defectuosos, como sí lo hacen algunos Estados miembros de la Unión Europea, donde la posibilidad de evidenciar mediante avances científicos la existencia de un defecto en el medicamento, no suprime la responsabilidad del fabricante farmacéutico. 


\section{Referencias bibliográficas}

Armada Carreras, Claudia. (2015). La Talidomida: desde la perspectiva del daño continuado, permanente y tardío. Universidad de Girona.

Bloch, Laurent. (2014). Produits de santé défectueux : désordre au sommet des ordres, Responsabilité civile et assurances, No.1, janvier, 2014, étude 1.

Borghetti, Jean-Sébastien. (2004). La responsabilité du fait des produits, étude de droit comparé. L.G.D.J, Paris.

Coderch Pablo Salvador y Ramos González Sonia. (2014). 150 casos de derecho de daños (2004-2014) 10 a edición. Indret, Revista para el Análisis del Derecho. Universidad Pompeu Fabra Barcelona : http://www.indret.com/pdf/1192_es.pdf

Comisión Europea (2019). Tipos de derecho de la UE. Sitio oficial de la Unión Europea: https://ec.europa.eu/info/law/law-making-process/applying-eu-law_es

Dubois, Charlotte.(2018). Contentieux du Mediator: le lien de causalité sous les projecteurs et une faute tapie dans l'ombre. Les Peties Affiches, No. 131u4.

Duran Fernández, A. (2016). Régimen de responsabilidad por daños ocasionados por producto defectuoso en Colombia. Cuadernos de la Maestría de Derecho, (s.v.) (5), 423-452.

Garber, Steven. (2013). The Legal and Institutional Settings. En RAND Corporation (Ed.), Economic Effects of Product Liability and Other Litigation Involving the Safety and Effectiveness of Pharmaceuticals (pp. 14-25). RAND Corporation.

Hernández Ramos, C. (2018). Responsabilidad por productos defectuosos en la Unión Europea Comentarios sobre un antes y un después de la expedición de la Directiva 347 [sic] de 1985. Revist@ e-Mercatoria, 17(1),87-121.

Hocquet- Berg, Sophie. (2018). Responsabilité médicale sans faute, responsabilité du fait des produits de santé défectueux, régime spécial, Jurisclasseur, fasc. 440-70,) (pp. 1-39).

Lomas Hernández, Vicente. (2016). El uso de medicamentos fuera de ficha técnica: la responsabilidad profesional del médico y la importancia de las comisiones fármaco-terapéuticas. Revista CESCO de Derecho de Consumo No 18/2016.

Mascret, Caroline.(1999). La loi sur les produits défectueux et les « éléments issus du corps humain ». Les Petites Affiches, Volumen 3, No. 23, p. 15.

Munar Pedro Octavio,(2013) La responsabilidad pro productos. Los grandes hitos de su evolución. en José Manuel Gual Acosta y Juan Carlos Villalba. Derecho del Consumo, problemáticas actuales, (pp. 173-212) Ibañez.

Navarro Mendizabal, Iñigo. (2014). Algunas cuestiones acerca de la responsabilidad civil en el caso de medicamentos en España. Revista de Derecho. Segunda época, No. 9 julio de 2014,161-184.

Navarro- Michel, Mónica. (2016). Daños causados por la Talidomida. La batalla legal que no cesa. Comentario a la STS de 20 de octubre de 2015. Revista de Bioética y Derecho, 37, 133-148.

Pardo, José Esteve. (2003). La protección de la ignorancia, exclusión de responsabilidad por los riesgos desconocidos. Revista de Administración Pública, Volumen 161, No. $1,53-82.7$

Parra Lucán, María Angeles. (2011). La Protección del Consumidor frente a los daños, Colección Derecho del Consumo. Editorial Reus. 
Parra Lucán, MaÁngeles. (2014) Responsabilidad por los efectos indeseables de los medicamentos (Con ocasión de la STS de 10 de julio de 2014: Responsabilidad de laboratorio por falta de información de los efectos secundarios de "Agreal"). Centro de Estudios de Derecho del Consumo CESCO, Universidad Castilla la Mancha. http:// blog.uclm.es/cesco/files/2014/10/Responsabilidad-por-los-efectos-indeseablesde-los-medicamentos-con-ocasi\%C3\%B3n-de-la-STS-10.7.2014-caso-Agreal-2. pdf

Pico Zuñiga, Fernando. (2018). El riesgo de desarrollo en la responsabilidad por productos defectuosos. Editorial Ibañez.

Ramos González, S. (2003). La responsabilidad por medicamento en el derecho alemán. Indret Revista para el Análisis del Derecho, (pp. 1-25). Universidad Pompeu Fabra. En Indret.

Ramos González, S. (2005). Responsabilidad civil por medicamento: el defecto de diseño. Un análisis comparado de los criterios de definición del defecto en España y en los EE.UU. Indret Revista para el Análisis del Derecho (pp. 1-27). Universitat Pompeu Fabra. En Indret.

Ruiz, Wilson. (2004). Responsabilidad medica en Colombia. Criterio Jurídico. Volumen (4), 195-216.

Sarrato Martínez, L. (2014). La responsabilidad administrativa, civil y penal en el ámbito del medicamento, Revista Jurídica de Navarra, Enero-Junio 2014. № 5 pp. 259-263

Superintendencia de Industria y Comercio. (2017). Radicado No. 16- 4244672-0. http://www.sic.gov.co/sites/default/files/files/Boletin-juridico/2017/ RAD16424467ProductoDefectuoso.PDF

Tabakian, Marcela. (2015). Evolución de la responsabilidad del fabricante en Estados Unidos y su influencia en el derecho comparado. Responsabilidad por Productos. Paseo por Estados Unidos, Europa, Latinoamérica y Uruguay. Revista de derecho de la Universidad de Montevideo, V 26, pp. 59-69.

Tamayo Jaramillo, Javier. (2016). Responsabilidad por productos defectuosos, Legis.

Valverde José Luis y Cabezas, María Dolores.(2009). La responsabilidad civil por riesgos de desarrollo en el ámbito de los medicamentos. En R. Barranco Vela (Dir.) F. M. Bombillar Sáenz (coord.), El acceso al medicamento. Retos jurídicos actuales, intervención pública y su vinculación al derecho a la salud (pp. 29-52).Comares.

Vaquero Pinto, M. J. (2017). Historia del caso de la Talidomida. Dies a quo del plazo de prescripción de la acción de responsabilidad civil. Prescripción y amparo constitucional. Derecho Privado y Constitución, Volumen 31, 275-316. doi: https:// doi.org/10.18042/cepc/dpc.31.07

Velásquez Posada, O. (2016). Responsabilidad civil extracontractual. Editorial Temis S.A.

Villalba, Juan C. (2012) Introducción al derecho del consumo. Ed. Universidad Militar Nueva Granada.

Villalba, Juan C. (2014). La responsabilidad por producto defectuoso en el derecho colombiano. Civilizar, 14 (27), 17-40. 


\section{Sentencias}

Corte Constitucional. (2006, 30 de agosto). Rad. C-742, Expediente D-6212. (CP: Marco Gerardo Monroy Cabra).

MacPherson v. Buick Motors Co. 217 N.Y. 382, 111 N.E. 1050 de 1916 ante el Tribunal de Apelaciones del Estado de Nueva York.

Tribunal Supremo - Sala Primera de lo Civil. (2012, 14 de julio). Sentencia STS 410-2014 (MP Rafael Saraza Jimena).

Juzgado de Primera instancia de Madrid, 19 de noviembre de 2013.

Audiencia provincial de Madrid, mediante fallo de octubre 13 de 2014,

Sentencia STS 10-7-2014 del Tribunal Supremo

Sentencia Audiencia Provincial de Barcelona (Sección 17ª , 7.6.2012),

\section{Normas europeas}

Unión Europea, Directiva No. 85/374/CEE del Consejo de 25 de julio de 1985, relativa a la aproximación de las disposiciones legales, reglamentarias y administrativas de los Estados miembros en materia de responsabilidad por los daños causados por productos defectuosos

Unión Europea, Directiva 92/59/CEE del Consejo, de 29 de junio de 1992, relativa a la seguridad general de los productos

Unión Europea, Directiva 1999/34/CE del Parlamento Europeo y del Consejo, de 10 de mayo de 1999, por la que se modifica la Directiva 85/374/CEE del Consejo relativa a la aproximación de las disposiciones legales, reglamentarias y administrativas de los Estados miembros en materia de responsabilidad por los daños causados por productos defectuosos.

Unión Europea, Reglamento (CE) No 864/2007 del Parlamento Europeo y del Consejo de 11 de julio de 2007 relativo a la ley aplicable a las obligaciones extracontractuales.

\section{Legislación nacional y extranjera}

\section{Colombia:}

Congreso de la República (Colombia) Ley 1480 de 2011.

\section{España:}

Ley 22/94 de 6 julio (1994) de responsabilidad civil por los daños causados por productos defectuosos.

Real Decreto Legislativo 1/2007, de 16 de noviembre, por el que se aprueba el texto refundido de la Ley General para la Defensa de los Consumidores y Usuarios y otras leyes complementarias.

Ley 40/2015, de 1 de octubre, de Régimen Jurídico del Sector Público.

Ley 4/1999 de 13 de enero, de modificación de la Ley 30/1992 de 26 de noviembre, de Régimen Jurídico de las Administraciones Públicas y del Procedimiento Administrativo Común.

Real Decreto Legislativo 1/2015 de 24 de julio, por el que se aprueba el texto refundido de la Ley de garantías y uso racional de los medicamentos y productos sanitarios. 